\title{
Through Collaboration to Sharawadji: Immediacy, Mediation and the Voice
}

Andrew Westerside: School of Fine and Performing Arts, University of Lincoln, UK* awesterside@lincoln.ac.uk

Martin Blain: Department of Contemporary Arts, Manchester Metropolitan University, UK*m.a.blain@mmu.ac.uk

Jane Turner: Department of Contemporary Arts, Manchester Metropolitan University, UK*j.c.turner@mmu.ac.uk

* Corresponding author. Email:

This article analyses the composition and experience of Proto-type's The Good, the God and the Guillotine (2014) from three critical positions central to the making process: Andrew Westerside, from the position of director and performer-singer; Martin Blain, from the position of composer-performer and Jane Turner, from the position of Dramaturge. It addresses an emergent connection between the sharawadji effect and the techno-sublime, made possible in this performance through the disturbances of technology and the 'technologically uncanny'. The objective of the article is twofold. The first is to demonstrate how both internally (to the performer) and externally (to the spectator) experiences of sharawadji and the sublime might emerge. Secondly, it proposes these experiences - notably sharawadji - as a product of the interdisciplinary process, and suggests in doing so a productive relationship between the often conflicting or unresolved dramaturgies that are created across performance disciplines.

Keywords: theatre, sound, sharawadji, techno-sublime, technological uncanny, composition

\section{Section One: Performer-Singer - Andrew Westerside}

\section{Sharawadji and the Sublime}

In Sonic Experience: A Guide to Everyday Sounds (2005) Jean-François Augoyard and Henri Torgue provide a working model for the sharawadji effect. Primarily a sonic phenomenon, sharawadji, as noted by Schafer in his foreword to their book, denotes 'an unexpected perception of beauty in the absence of any discernable order or arrangement' (Schafer 2005, xv). The condition of sharawadji, for Augoyard and 
Torgue, contains a 'feeling of plenitude' either through the 'absence of design', or of the 'unexpected', which '[has the potential to] transport us elsewhere' $(2005,117)$. In his foreword Schafer highlights 'the din or racket of carnivals [and] demonstrations' as being particularly relevant to understanding sharawadji in relation to sonic environments. He concludes that 'perceptive confusion gives way to an inexplicable aesthetic pleasure' (2005, xv). 'In this brutally present confusion', argue Augoyard and Torgue, 'we lose both our senses and our sense' $(2006,117)$.

As an experiential concept, sharawadji is irresistibly close to the Kantian sublime: a sensorial and cognitive overload, 'found in an object even devoid of form, so far as it immediately involves, or else by its presence provokes a representation of limitlessness' (Kant 1987, §23, 90). As Shaw notes, the sublime 'refers to the moment when the ability to apprehend, to know, and to express a thought or sensation is defeated. Yet through this very defeat, the mind gets a feeling for that which lies beyond thought and language' (2006, 3, our emphasis). For Augoyard and Torgue, an 'absence of design', for Kant, ‘an object devoid of form'; a ‘brutally present confusion', versus a 'defeat' of thought and sensation. Schafer draws similar comparisons, while proposing a careful distinction in which 'sounds become sharawadji less by their excessiveness than by their implausibility' (Schafer 2005, xvi). If it is at all sublime, he contests that 'Sharawadji is the sublime of the everyday - a subtle sublime, without splendour or theatricality, arising from a brouhaha, sonic muddle, or other strangely discordant sound' (xvi). In this article, through both theatrical and musicological analysis, we propose a more porous relationship between the twin-concepts of sharawadji and the sublime in instances where either a) the experience of the sublime is technologically facilitated or b) the processes and demands of interdisciplinary collaboration result in what we call here 'conflicting 
dramaturgies' - ruptures analogous to Augoyard and Torgue's carnivalesque 'din' of sharawadji.

\section{The Good, the God and the Guillotine}

Developed over a three-year period, beginning in late 2010 and culminating in a UK tour which concluded at Nottingham Playhouse's 'NEAT' ${ }^{\text {' }}$ festival in 2014, Prototype Theater, along with collaborators Manchester Metropolitan University Laptop Ensemble (MMUle) $)^{2}$, Digital Artist Adam York Gregory and Lighting Designer Rebecca M.K. Makus, undertook a practice-as-research project led by questions of interdisciplinary collaboration, dramaturgy, and adaptation. Structurally, The Good, the God and the Guillotine (henceforth: TGTGATG) re-imagined Albert Camus's 1942 existentialist novel, L'Étranger (The Stranger), as a music-driven, performancecum-concert in thirteen parts. Each part, of which there were eleven 'chapters', a prologue and an epilogue, takes the form of a song/musical composition. Each 'chapter' of the performance responds theatrically and musically to each of the chapters, in sequence, of Camus's original, capturing their 'essence' or 'mood', as well as key moments of the plot of the novel, using an album-like structure.

\section{Insert Figure 1}

Figure 1: The Good, the God and the Guillotine (2014): 'Prologue' (photo by Conan Lawrence; courtesy of Prototype Theater).

\section{Insert Figure 2}

Figure 2: The Good, the God and the Guillotine (2014): 'Chapter 9: A Small Room that Smells of Darkness' (rehearsal image) (photo by Adam York Gregory; courtesy of Proto-type Theater). 
TGTGATG features six performers: three performer-singers and the three electronic musicians of MMUle. As seen in Figure 1, the piece is performed behind overlapping strips of black gauze, which also serves as a projection surface. Behind the gauze, downstage left, is a rostrum, accessed via steps. The rostrum is positioned immediately downstage of a rear projection screen of matching width. Stage right stand three platforms of varying heights. On each platform is a table from behind which the three MMUle musicians perform. The front (gauze) and rear (screen) projection surfaces, while operationally separate from one another, are in dialogue with one another insofar as the animations which play on and across them are designed to be complementary in the setting of place or mood. In Figure 1, taken from 'Prologue', we see the rear projection of a scrolling double-helix, and in front of that the silhouette of a performer preparing to sing. The front gauze animation (always black-and-white) is an abstract effect, which in 'Prologue' is a duplicate of the double-helix on the screen, but moving at a slightly slower pace. In this way, the performers inhabit a space 'between' the mediated spaces - indeed, between the work of the performance and the embodiment of a figure (in the case of the silhouette, L'Étranger's male protagonist, Meursault).

None of the performer-singers are trained vocalists - they can hold a tune, and do not affront the ear, but their sound is raw and in no sense classical. Each voice is connected directly, via SM58 microphones, to the laptop of an MMUle performer, who in turn has the ability to manipulate, amplify, scratch, distort or shift the voice as it is sent out through a P.A. using custom built 'patches' in visual programming language MaxMSP (Figure 3). This is controlled in a variety of ways, from simple keyboard and touchpad commands to the pressure and speed of a touchpad swipe, to 
an external controller with analogue function (in this case a video game controller similar to those used with the Microsoft Xbox 360 console).

Insert Figure 3

Figure 3: The Good, the God and the Guillotine (2013). A patch in the visual programming language MaxMSP. (photo by Martin Blain; courtesy of Proto-type Theater).

\section{Theatre and Music}

I write the following sections from the positions of both performer-singer and director. I delineate between the conceptual and aesthetic aims of TGTGATG, and also what it was actually like - as a performer-singer with an untrained musical voice - to engage in the 'work' of the performance. Early in the creative process - with our history and skills firmly in the field of contemporary, experimental performance - the Proto-type Theater members were interested in working with something that challenged us musically. Our most recent pieces to that date (Whisper, 2007; Virtuoso (working title), 2009; and Third Person (redux), 2010) had demonstrated an interest in engaging with mediatising technologies and constructions of the intermedial as theorised by Chapple and Kattenbelt (2006), and Bay-Cheng, Lavender, Kattenbelt and Nelson (2010). Following Kattenbelt (2008), the collaborators involved in this project conceived of the adaptation of L'Étranger as a transmedial process: 'referring to the change from one medium to another' (Kattenbelt 2008, 23). As non-musicians, and most importantly, as non-singers, the Proto-type Theater members' artistic interests were also concerned with the relationship between the 'raw' voice, the untrained musical voice and the ways in which those voices could interface with MMUle/MaxMSP to create sounds and soundscapes that might transcend the implicit humanness of the voice - what Philip Brophy calls that inevitable implication of a 
'human producer', 'the inalienable vessel of human emotion' (Brophy 2010, 361). What might it be like, we wondered, to become virtuosic, better, to sound good? What can our voices become, where can they go, in the moments when they interface with the machine?

As theatre-makers, but self-identified non-musicians, we did not consider our rendering of L'Étranger as a drama set to music insofar as Kattenbelt's articulation of the transmedial demands that we recognise the significance of a 'transfer' $(2008,23)$ of form. As Lehmann observes, 'the tendency towards a musicalization [...] in postdramatic theatre' (Lehmann 2006, 91) in turn creates a kind of 'auditory semiotics' through which - in the face of the 'dissolution of dramatic coherence' - we apply our 'sense of music and rhythm' (91). This tendency, which Roesner articulates as the shift from 'understanding musicality as a normative category' to one which 'functions as an umbrella term which covers a range of aspirations of one art form (theatre) towards another (music)' $(2014,9)$ became the methodological foundation of the work insomuch as a shared interdisciplinary language was allowed to develop. $T G T G A T G$, then, is a composed, music-theatre performance following Lehmann's definition of 'musicalization'. Its experience (both in the doing and the seeing/hearing) is one of inherent musicality, the intersection of those two distinct forms in live collaboration with each other.

As Gough notes in 'The Art of the Loop', 'while highly visual' TGTGATG is 'vision orchestrated as hearing' $(2016,107)$. As such, the terms performer-singer and spectator-listener are of considerable importance to us. ${ }^{3}$ The hyphen identifies a 'both-and' position indicating that one term is not privileged over the other in a hierarchy of experience or creative importance. 


\section{Performing Sharawadji and the Techno-Sublime}

While Turner (in Section Three) will discuss the sharawadji effect as felt by the spectator-listener through a synthesis of elements, here I will explore how, as performer-singers, the execution and register of the sung elements of the performance are played out upon, or perhaps through (even, in spite of) a sense of sharawadji in the moment of performing.

At the very start of the performance, the performer-singers enter and test their microphones, and in so doing test also the 'connection' to their designated MMUle musician. They speak the letters $\mathrm{T}$ (Tuh), G (Guh) and A (Ah) six or seven times, in seemingly random orders. 'These sounds', observes Gough, 'are simultaneously recorded by the laptop musicians, and are played back as an arpeggiated rhythmic sound loop' (108). The loop is used as an ostinato ${ }^{4}$ for the 'Prologue'. 5

Over the loop, the performer-singers sing (in turn), the name of three (of the four) nucleobases found in DNA:

Thymine

Guanine

Thymine

Guanine

Adenine

Thymine

Guanine (Proto-type Theater 2014)

Each performer-singer sings a slightly different melody, none of which sit in conventional groupings of notes. Moreover, every time the theme is re-introduced it is with a slight variation. Never repeated twice, these small changes in the pitch material cause significant problems in pitch intonation for untrained musical voices. Later in 
the 'Prologue', the performer-singers are faced with a number of significant (musical) challenges. The text is as follows:

A man (a man)

Doesn't need any god

To live his life

What happens now

Happens now

It doesn't happen twice

We're only strands

We're only cells (Proto-type Theater 2014)

Here, the melody, which is not diatonic, is built on intervallic relationships of fournote groupings. In the moment of performing, the performer-singers are not intentionally attempting to 'hit' the desired note - 'I am going to sing A followed by F', and so on - but are rather trying, via memory alone, to sing what they remember the melody sounding like. Where this becomes especially challenging is that there is no 'foothold' for them to guess how to intone pitch - that is, because the melody operates outside of recognisable key signatures, they must rely solely on memory, in this case, the memory of the piece sounding good. This, in addition to the overlapping and half-repetition of lines, where one singer might be purposefully half a bar or beat behind another, makes for a disorienting experience in which - for the performers the sound material 'loses its sense' (Augoyard and Torgue 2005, 118). Significantly, this 'unpredictability and diversity', this 'interruption of sonic rules' creates the kind of sharawadji effect 'difficult to apply [to] the domain of structural and composed music' (122) as the performer-singers, through this disorientation, experience 
something which might be described as the 'rapture' of sharawadji. Performer-singer Gillian Lees (personal communication, 2013) comments:

It's like a massive relief, but pleasurable too. You feel so lost in it, and then you're in the middle of a song and you think you know what you have to do or sing but you're not quite sure. And then the sounds come out of you and it's strange because you do kind of know what to do, but there's a feeling that you're not fully in control of it.

For Lees, then, sharawadji emerges from the sense of elation - here a kind of pleasurable relief - that one feels at successfully navigating the apparently formless or disordered sequence of notes one must produce in order to perform (or indeed 'keep up') with the work.

This experience produces a performance quality, in the case of TGTGATG, which is unique to the untrained musical voice. Where recognition and sensibility breaks down - as in the sublime experience - the performers find an urgency in their negotiation of the space/world of the work, which is possible only because of this lack of comprehension. It creates an energy in performance that teeters, on the edge of failure, of nothingness, of the inability to speak (or sing). Importantly, again as with the sublime, the overwhelming and consuming feelings of struggle, of a lack of adequate concept or tools with which to encounter the object of our intuition, has as its counterpart a great joy.

Indeed, that the felt sense of sharawadji on the part of the performer-singers is facilitated (caused?) by technology marks the beginning of the border-territory between sharawadji and the techno-sublime, rather than the sublime of a strictly Kantian formation. As Augoyard and Torgue note, 'the computer allows an exploration of psychoacoustics favouring sharawadji ${ }^{6}$. They posit that 'certain acoustic parameters' - including high intensity and rhythmically irregular sound - 
'seem to favour the sharawadji effect' $(2005,122)$ insofar as the digital sound generated by the computer is capable of a broader, more complex set of pitches and frequencies than traditional acoustic instrumentation. In this sense, as the looped voice is fed back to itself as a kind of backing track, the seemingly limitless potentialities articulate the relationship between sharawadji and the techno-sublime.

Sharawadji is concerned with experiences of (often inexplicable or surprising) beauty. The sublime, however, in its Kantian formation, is not beautiful. While not its opposite, 'the sublime is serious where beauty is frivolous' (Gilbert-Rolfe 2001, 85). In the strictest Kantian sense, then, Augoyard and Torgue need not make sharawadji something which 'carefully distinguishes' $(2006, \mathrm{xvi})$ itself from the sublime insofar as, if the former is concerned with sonic textures that produces experiences of beauty, then it is de facto not sublime. While both experiences are aesthetic, for Kant, the experience of the sublime 'gave fleeting access to ideas or things beyond the noumenal world' (Westerside 2010, 196); supersensible ideas like reason, and freedom, and to the sense of 'human morality' (110).

But in the 'loop', the voice confronts itself, disembodied; agency is wrested from the performer-singer by 'invisibility itself, the air, [...] filled with electronic signals' (Gilbert-Rolfe 1999, 54). As vocal melodies pass through the lengths of XLR cable, to the motherboard of a laptop, they become the property of the machine. As Barbara Bolt proposes: in the techno-sublime:

... there is no longer a concern with the re-assertion of the 'self' in the face of the sublime event. Rather I argue that in this encounter there is a collapse in boundaries as 'I' dissolves into the collective techno-experience. (Bolt 2002) 
Thus, as digitally processed sounds are re-uttered, re-sung, one's own voice reappears, assimilated with the computer, the technology 'replacing the world it was supposed to facilitate with quite another, [a] nightmare of a technology that pretends to be useful but instead takes over' (Gilbert-Rolfe, 1999, 85). Might it be the case, then, that the techno-sublime - if such a thing is present in TGTGATG - is an experience that rests at the limen of sharawadji and the sublime? If sharawadji, this 'brutally present confusion', is 'favoured' psychoacoustially by the computer, is it that the felt sense of 'loss' or 'being lost' by the performer-singers is a rendering of Bolt's 'collapse'? Here, where the performer is consumed by, and 'dissolves into' the sonic landscape of the performance, is it that we find, in the 'din', the place where the beautiful and the sublime touch?

\section{Section Two: Performer-Composer - Martin Blain}

The following section explores some of the compositional strategies I developed as part of MMUle, and will focus on strategies that have the potential to provide the conditions for sharawadji.

\section{Composing Sharawadji}

\section{Melodic fragments}

During the first block of workshops the collaborators explored the musical potential and possibilities of bringing together performer-singers with a laptop ensemble. ${ }^{7}$ 'Prologue', as discussed by Westerside above, also provided the raw vocal materials for the three performer-singers in two of the 'chapters' I will discuss in more detail: 'Chapter 7: Monsieur Antichrist' ${ }^{\text {' }}$ and 'Chapter 9: A Small Room that Smells of Darkness'. ${ }^{9}$ Whilst challenging for the 'untrained' performer-singers, the resulting 
vocal textures produced by the three performer-singers in the creative process were particularly impressive. The performer-singers reported that the vocal experiments had resulted in a sound-world that was new and exciting for them but the fear of recreating this new found sound in live performance was terrifying and therefore, at this stage in the process, not desirable to continue. This process reminds me of how Robert Lepage describes his own process of making theatre where he suggests that it is something that 'takes shape in flight, when its meaning and direction escapes us, when it becomes a rebellious beast that we're unable to cage' (Lepage in Charest 1995/1997, 159). The 'beast' here for the performer-singers was working in non-tonal musical structures. Unlike traditional tonal structures where pitch and triadic chord structures are organised into hierarchical relationships, in the initial vocal improvised workshops performance pitch relationships and harmonic organisation principles were determined by other means. As Augoyard and Torgue suggest, '[t]o the uninitiated ear, contemporary music follows no rules' $(2005,118)$. This would suggest that a process of familiarization with compositional practices is of benefit. For the performer-singers familiarity with the sound world was achieved through repetition during the rehearsal process.

\section{Causal Relationships}

Developing a causal relationship between performative action (cause) and resulting sound (effect) in 'Prologue' was strategic: it provided the spectator-listener with immediate access to what the sonic relationships were between the utterances of the performer-singers and the laptop musicians. 'Prologue' establishes physical as well as sonic relationships for the benefit of the spectator-listener and this may be of benefit for the spectator-listener when sonic relationships may appear 'disturbed' later in the 
work. With the melodic fragments repeated both in their original and transformed forms throughout the 'Prologue' this also enabled the spectator-listener to become familiar with the sound world for this particular compositional strand of TGTGATG. The melodic fragments introduced in 'Prologue' are further developed in 'Chapter 7: Monsieur Antichrist' through the use of digital audio processing and it is this recontextualized setting of the familiar melodic fragments that may encourage the sharawadji effect.

'Chapter 7: Monsieur Antichrist' presents with minimal text.

I don't believe in

I don't believe in

I don't believe in

God (Proto-type Theater 2014)

One of the key compositional strategies to emerge through experimentation with the Monsieur Antichrist text was in exploring extreme contrasts of musical parameters. The performer-singers worked with their assigned laptop musicians and developed transformed vocal timbres in the form of recognisable angelic high-pitched voices for the two female performer-singers and a distorted unrecognisable low-pitched vocal sound for the male performer-singer. The 'disturbance' of the voice creates ambiguities of space, temporality and liveness and this is manifest in the score on many levels. For example, the illusion of two simultaneous audio spaces is established through the use of reverb added to the high-pitched female voices, contrasted with a pitch-shift effect added to the male voice set to a low frequency. Temporal ambiguities are created through the vari-speed playback function set up through the bespoke MaxMSP patch developed for TGTGATG. Here, the angelic 
high-pitched female vocal sounds are captured live in performance and played back at different speeds to create multi-pitches and thicker vocal textures. This process also demonstrates the ambiguities of liveness as the capturing of the vocal signal and the playback speed of the resulting audio sample is controlled and performed by the laptop musician through an external games controller. This action (performance) is made evident to the spectator-listener and is an example of MMUle developing a causal relationship between the seeing of an action and the hearing of a resulting sound.

The existential angst of Monsieur Antichrist is realized in the score through a process of sonic transformation from the sound of the machine to the sound of the human - a Pitch Shift plug-in effect was used to alter the spoken male voice to a sound texture that could not be understood as speech. At the beginning of the spoken section the full effect was used; by the end of this section the effect has been reduced so that the sound of the human voice reciting the text 'I don't believe in God' is now revealed. In counterpoint to the spoken text, the two female voices share a melodic line through the technique of hocket ${ }^{10}$ (produced by alternating the pitches of a single melodic line between the two separate voices) and the resulting sound is processed through a reverb effect. This transformed the two female voices so that the articulation of a single pitch could be heard and the resulting sustained pitch could be treated with the effect. What we heard was an angelic chorus of high-pitched female voices; what we saw were two female singers effortlessly vocalizing sustained sounds. The 'disturbance' of the angelic voices is further enhanced through the use of articulating each of the pitches through the syllables contained in the text. The resulting sound is as follows: i-e-I-e-do-be-in-o...... I-don't-be-lieve-in-God. Again, when the text, 'I don't believe in God' is heard in the female voices, the reverb effect 
is reduced so that the text is heard more clearly. The intention is that at some point near the conclusion of this 'chapter' the first recognizable articulation of the phrase 'I don't believe in God' occurs in all vocal parts and this is unpredictable and unexpected. The pitches sung by the female voices, being a variation on the 'Prologue' fragment, provides some familiarity for the spectator-listener within a section of the work that may appear unusual.

The harmonic support provided by the laptop ensemble makes use of apparent static harmonic structures that shift imperceptibly through the 'chapter'. This is achieved through the development of a series of 6-note chords moving freely within a post-tonal harmonic structure and performed, manipulated and shaped through the processes applied by the three, laptop musicians. The computer musicians control the 'imperceptible' harmonic shifts as they realized the harmonic material (through the manipulation of individual pitches) and the computer-transformed voices of the performer-singers.

\section{Immediacy, Mediation and the Voice}

'Chapter 9: A Small Room that Smells of Darkness' is concerned with musical structures and textures that appear to disorientate and confuse the spectator-listener. The text is as follows:

There is a room

So small

That the only thing

That fills it

Is the smell of darkness. (Proto-type Theater 2014) 
This 'chapter' provided an opportunity to explore further the compositional insights exposed through the development of the 'Prologue' and 'Chapter 7: Monsieur Antichrist'. In 'Prologue', the immediacy of the interaction between human and machine was exposed through the necessity to establish causal relationships between the performer-singers and the laptop musicians. Without this it would have been almost impossible for a theatre audience to engage meaningfully with the sonic relationships developing within the musical score. In 'Chapter 7: Monsieur Antichrist' the use of the laptop ensemble to develop sonic structures that complement and accompany the mediated voices of the performer-singers provided additional clue-like strategies to help the spectator-listener 'read' or, at the very least, engage with the performance.

Whilst the relationship between performative action (cause) and resulting sound (effect) remains an issue for laptop performers engaging in 'live' performance, within the world of electroacoustic music performance, the issue of causality that connects seeing to hearing does not appear to receive the same level of attention. In fact, Simon Emmerson, when discussing cause and effect directs his attention to the relationship between the 'hearing' of a cause and the 'hearing' of an effect (Emmerson 2011, 269). Within this particular tradition, notions of compositional design are realized and developed through what Emmerson defines as 'the sounding flow' $(2007,30)$. Emmerson's notion of the sounding flow was particularly useful in the development of 'Chapter 9: A Small Room that Smells of Darkness'.

The opening section of 'Chapter 9: A Small Room that Smells of Darkness' is a reworking of the angelic high-pitched female vocal writing from 'Chapter 7: Monsieur Antichrist'. The long durational pitches are processed through a delay effect that repeats the captured pitch many times in a short duration and creates a high 
intensity rhythmic pattern that is performed through the MaxMSP patch. The sample is further processed to create additional instrumental parts that, when combined, function as individual parts similar to traditional counterpoint. When this high intensity section fades we are left with a low frequency drone. Two female voices sing a simple melody and the intention is for the two female voices to create a moment of intimacy with the spectator-listener.

The human voices are processed through a dynamic compressor and this helps to create the illusion of intimacy. The compressor reduces the dynamic range of the signal for both female voices and the performer-singers are instructed to sing quietly into the microphone at close range. Close singing into the microphone amplifies the lower frequencies of the female voices and this is known as the proximity effect; when combined with dynamic compression the resulting vocal sound presents as being close to the spectator-listener in the performance space. Here the audio illusion is one of intimacy.

Both female performer-singers sing close to the microphone; they sing quietly; they are still; the space is dark and the spectator-listener is encouraged to be transported into the closed world of Monsieur Meursault. The spectator-listener may experience this as a shift from an external shared space to a private space inside the mind's ear of Monsieur Meursault. To get to this place the laptop ensemble prepares the spectator-listener by developing the sounding flow of external sounds (experienced by all) where sounds present as disorientating, unpleasant, out of the ordinary and to some ugly. The sounding flow provides some shaping of the sounds: the morphology of the sounds is now important and the laptop musicians control this. During the final section of this 'chapter' the angelic voices return, ghost-like, as if 
trapped within the machine. A delay effect is added to the angelic voices and this enhances the illusion of the performance space becoming larger - the performance space has transformed from the intimate space occupied by Meursault to a shared space now occupied by the spectator-listener. Throughout this 'chapter' rhythm is discontinuous: sounds from the natural world such as traffic noises, bird and environmental sounds are used to illustrate external realities within the composition. The sounds used can be described as high intensity as demonstrated at the opening and closing sections of the work; and low frequency sounds are used in the middle section of the work to establish a moment of calmness.

\section{Entering Sharawadji}

Augoyard and Torgue, in attempting to capture the essence of sharawdji, suggest that ' $[\mathrm{u}]$ nbridled and unintentional structures disrupt the nature-culture binary and reveal new forms of life beyond their disorder, which paradoxically can be completely fabricated' $(2006,118)$. Postmodernist thinkers are suspicious of the notion that composers define unifying processes, that listeners identify them and that analysis can be used to decode them. This is not my intention here. My intention has been to provide examples of processes and practice where the conditions of sharawadji are likely to manifest as defined by Augoyard and Torgue. Kramer defines 'perceptual unity' as representing a shift in emphasis: the personal unifying experience of the listener is independent of what the composer may have intended. He suggests that perceptual unity 'resides in relationships - but not among aspects of the music-outthere but among music-in-here' (Kramer 1995, 14). The so-called active listener is then encouraged to make sense of apparently unpredictable musical structures: an experience that could mobilise the techno-sublime. As Turner has argued elsewhere: 
'the technosublime is an available experience, a consequence of the spatial and aural immersion and technological disorientation that compound to simultaneously create both critical space for reflection and an immersive experience' $(2016,33)$. Alternatively, they can just let the beauty of the resulting structures wash over them and aspire to the condition of sharawadji, thus reaffirming the idea of a borderterritory between sharawadji and the techno-sublime.

\section{Section Three: Dramaturge/Spectator-Listener - Jane Turner}

Having identified that TGTGATG activated aspects that affected both a technosublime and/or sharawadji experience from a performer-singer and composerperformer perspective, the article is now going to engage with the impact of these concepts on a spectator-listener experience. I will offer a personal evaluation of the affective experience of observing the development of the project as well as the performance.

Initially I followed the creative development of this project as ethnographer. As an outsider observing the insiders in their creative making, each of our meetings engendered creative pleasure and 'dizziness' (Augoyard and Torgue 2005, 121). We did not refer to the meetings as rehearsals as they were occasions for developing material, trying out ideas rather than rehearsing in a conventional sense. Paradoxically the performers spent the time between the scheduled meetings rehearsing; this preparation was usually a solitary occurrence, hence why the meetings afforded unexpected experiences and a heightened sense of 'dizziness'. The meetings were cacophonous and disorientating but the state of disorientation began to settle into something that became familiar for the makers as they began to identify points of contact in the sound structures and construct patterns in the seemingly random 
relationships between the conflicting dramaturgical strands being developed by each of the artists. TGTGATG radically split the dramaturgical strands and encouraged each performer, light artist and animator to develop their own dramaturgical weave. While this allowed for their individual responses to the novel to be articulated, it also caused a potentially incoherent stratification of textual levels, leading to a seemingly unruly and disorientating experience for the spectator-listener. In the overarching architecture of the performance performer-singers, musicians and spectator-listeners sought to apprehend patterns from the excess of textualities: a carnivalesque 'din' of unresolved compositional scores that at times appeared to compete and collide with each other in the space.

My 'outsider' role later morphed into that of a dramaturge and I became the first spectator-listener. In this capacity I allowed myself to be immersed in the sound environment and seduced by the flickering images projected onto the numerous screens that proliferated in the performance space, only latterly realizing the seeming inconsequentiality of the performer-singers as they struggled - sometimes literally to compete with the digitally produced materials that besieged their space. However, I became mindful of emerging counterpoints in the conflicting dramaturgies that might afford parallel experiences between the performer-singers and the experiences being fashioned for the spectator-listener: what could be described as an experience of the existential sublime that here is initiated by what has already been established as the sharawadji effect.

\section{A Spectator-Listener Account}

Sharawadji is described as affording a 'perceptive confusion' from an evident disorder or unruliness (Augoyard and Torgue 2005, 118). Similarly, Crowther, in his 
account of the existential sublime, describes a quality of a sublime art object, such as a theatre event, as effecting an 'affective jolt' $(1993,126)$ to our (in this instance the spectator-listener's) sensibility and disposition.

For a theatre event to be ascribed with the properties of the sublime and/or sharawadji, it must be rendered bizarre or out-of-the-ordinary. Crowther suggests that while, on the one hand, we seek routine and monotony in our existence, we also require disruption, an experience that intensifies and revitalizes our sense of being alive. My account demonstrates how the experience produced by TGTGATG offered an affective experience to the spectator-listener (in this instance, me) because it afforded sensory disorientation and an affective jolt where both are mediated through technology.

This was a performance that was resonant with anxieties connected to late capitalist western society. The choice of Camus's text L'Étranger featured, if abstractly, Meursault returning home for his mother's funeral, his killing an Arab man on the beach, his imprisonment and execution - here depicted as the body's release and return to elemental compounds. As Crowther comments, 'a spectacle of mortality... rejuvenates our sensibility... our very sense of being alive - is intensified into a felt quality, precisely because it is directly underscored by some actual or represented negation of life' (127). Death, murder and execution, and the slow strangulation of the technology did indeed become a 'felt quality'.

The interweaving of digitally produced sound and visual animation subjected the spectator-listener to a relentless bombardment of what, on one level, appeared to be familiar textual layers, such as three performer-singers singing about such banal subjects as the horror of losing a mobile phone or sitting in a small room alone. However, the banality of the subject matter was permeated by an uncanny sense that it 
was a distraction from an ominous tension inherent in the opacity and intangibility of the performer-singers, who were obscured and frustratingly always just beyond my grasp, being trapped behind the black gauze.

An incessant flow of animated images projected onto the screen behind the three performer-singers depicted a sperm impregnating a life cell, an evolutionary development of human life - where the human forms are morphed into replica images of the performers whose heads, latterly, were replaced by digital circuit boards. However, while the scrolling animated account of human evolution created a steadying monotonous rhythm and the sound score was underpinned by a drone that also reaffirmed a quality of seductive monotony, the interweaving of the disparate textual layers had the effect of enlivening and intensifying my sense of being alive at a sensorial level. I felt the sound-score inhabiting my body, producing a sense of heightened anxiety that was only fully appreciated when eventually the sound stopped and I experienced my body being released from the grip of technology. Home-Cook describes a similar experience in his account of Ether Frolics where an aspect of the sound design included what he calls a 'false sound bed' $(2015,115)$. He reports that he had been confronted with a

...relentless barrage of noise... eventually giving way to the 'silence' of the space. Then after some time, something remarkable happens: the silence I thought I had been listening to is suddenly 'switched off'; what I had been listening to was in fact a false sound bed. (115)

Similarly, in TGTGATG, while I thought the sound had stopped in actuality I was still immersed in a technologically controlled, deceptive silence, a silence he describes as uncanny: 'physically present but perceptibly absent' (115). Home-Cook describes such deception as 'sonic stealth' (115), a means of drawing my attention to processes of listening and hearing. However, in TGTGATG, the sonic stealth could be 
considered to be even more insidious as it further indicated the capacity of digital technologies to manipulate our sensibilities: deceiving and masking my sense of what constituted silence, refusing to allow me an experience of what it felt like to be unplugged - until I was finally released from this dystopian world.

\section{Technological Anxiety}

Perhaps one of the most startling 'chapters' that illustrated and evoked a sense of both the intense anxiety promoted by the use of technology and 'sonic stealth' as a compositional strategy was 'Chapter 9: A Small Room that Smells of Darkness'. The 'chapter', as discussed previously by Blain, effected an intensely compressed digital soundscape that paradoxically emulated silence and isolation. The intensity of the soundscape was mirrored by the animation that depicted a visual equivalent of white noise: a black screen with numerous motes of dust demonstrated that an absence of sound and light was always illusory; we cannot escape into a space of absence. In this instance, such a space replicated a sensation such as tinnitus, an inescapable sensation of too much sound. We never escape into emptiness as such: a space is always contaminated by detritus; the noise of our own bodies; the noise of the machine. Here the spectator-listener and Camus's figure of Meursault became merged most explicitly for the first time in the performance. I was confronted with the notion that I was one and the same, both immersed - imprisoned if you will - in a tightly coiled hell. Camus's Meursault suffered from an existential anxiety that was here replicated by a profound technological anxiety.

It is important to recognize that $T G T G A T G$ was not a dramatization of Camus's novel. These performer-singers did not embody characters from L'Étranger, rather they offered a semblance, an uncanny trace of the outsider in all of us. The 
huge gauze across the front of the playing area required me to see as though through a glass darkly; it was a frame that orientated and focused me, compelling me to gaze fixedly. The compulsion to gaze may be ascribed to my experience until the moment in 'Chapter 9' when the effect of the gauze shifted and became more like the lens of my eye, a limen through which I was being invited to view the world; a view that was dirtied by static, interference, fleeting semi-transparent images of insects, dogs: phantasmagoria. Similarly, the soundscape also offered a sound version of phantasmagoria: a ghosting of voices, voices captured, processed, played back. This was the technological uncanny. (Till 2012)

Nicholas Till describes his recent work as exploring the 'technologically uncanny' (2012). He defines this as,

$\ldots$ an effect that arises through the blurring of nature/culture distinctions, both at a phenomenal level (the electronic that sounds human, or vice versa; the anthropomorphism of machines) and the conceptual level (do we hear technologically produced sounds/images as phenomena of nature or culture; as 'mediated' or 'immediate'?). (187)

Till's discussion of the relationship between vocally produced and digitally produced sound resonates with the experience offered by $T G T G A T G$, especially in terms of the challenges experienced by the spectator-listener regarding what sounds were occurring live in the space and what had been previously recorded. Who was in control of the performance - the live performer singing in front of us; the musician standing at the laptop; the animator absent, from view; the machine itself?

As a listening-spectator, I witnessed the performer-singers struggle to cope with the complexities of existence in the face of an overwhelming technologically controlled environment: a struggle that paralleled the struggle depicted in Camus's novel. Here the technology threatened their ability to retain control of their embodied 
existence as their voices were disembodied and digitally processed. As Crowther points out, the sublime, in a postmodern context such as $T G T G A T G$, can be activated by 'the pushing of a button, the depression of a key' $(1993,131)$. The playing out of an existence was a simulacrum, a metatheatrical commentary on the actual human beings performing in front of me whose identities were obscured, whose presence was compromised and whose place in the theatrical landscape was infected by their technological situated-ness. I was led towards a realization that this was my existence. What I initially saw was the machine as 'slave' to the musicians but slowly the technology became a dominant and controlling force.

For instance, throughout the performance a series of square boxes, lit inside by nine LED lights, representative of a digital circuit board, were carried, stacked and used like drums. In 'Chapter 9' the boxes are accompanied by the performer-singers now wearing masks that replicated the boxes (see Figure 2). The LED masks were movement sensitive and thus pulsed as the performer-singers moved their hands. As a spectator-listener I witnessed the heads of the figures having all been subsumed by technology; thus embodiment, for the performer-singers and (vicariously) the spectator-listeners had deferred to technology. Gilbert-Rolfe states that technology has become the dominant regime and consequently the techno-sublime seeks to 'obviate the body'; the face is rendered as merely a surface that now 'belongs to technology' $(1999,113)$. The performance queried whether the voices of the performer-singers were able to resist the potential strangulation of the tangled webs of technologies. And further, whether the collaborators were complicit in the effacement or obviation of the body by technology.

As a spectator-listener I was confronted by the implications of this danse macabre with technology and experienced a realisation that the mediated experience 
of the spectator-listener emulated that of the performers, thus generating not empathy but a commensurable concern of being controlled by technology. I was lured in, seduced by the visual and sonic splendor produced by technology - a not dissimilar seduction to that initially experienced by the performer-singers who were excited at being made into singers by the technological processing and took pleasure in the perceptual confusion of the textual materials they were playing with, as I had done, but latterly realized, to return to Gilbert-Rolfe, that the technology was a 'nightmare... that pretends to be useful but instead takes over' $(1999,85)$.

\section{Conclusion}

TGTGATG was a multi-faceted research project which attempted - in addition to making an arresting piece of touring music-theatre - to ask questions about collaboration, methodologies of practice, authorship, adaptation and technology. Here, we have tried to establish ways in which the compositional structures and musical affects of the work (for both performer-singer and spectator-listener) sit at a nexus of points between notions of sharawadji and the techno-sublime. The significance of these meeting points, for theatre and music practices which, for Roesner, 'move towards' the other, is that the notion of sharawadji has hitherto been occluded from the analysis of composed music and performance by virtue of the claim from Augoyard and Torgue that Sharawadji as a concept is 'difficult to apply $[\ldots]$ in the domain of structural and composed music.' $(2005,122)$. Here then, we offer a series of practices, collisions, and experiences, which enable an affective sense of sharawadji in contemporary, composed, theatre practice. In this applied context, sharawadji 'grounds' the sublime in the material structures of performance and 
provides a means of articulating the sensorium of experience enabled by Lehmann's 'musicalization' of the postdramatic stage.

\section{References}

Augoyard, Jean-François, and Torgue, Henri, eds. 2005. Sonic Experience: A Guide to Everyday Sounds. London: McGill-Queen's University Press.

Bay-Cheng, Sarah, Lavender, Andy, Kattenbelt, Chiel, and Nelson, Robin, eds. 2010. Mapping Intermediality in Performance (Mediamatters). Amsterdam: Amsterdam University Press.

Blain, Martin. 2016. "Managing live audience attention in the age of digital mediation: The Good, The God, and The Guillotine." In Experiencing Liveness in Contemporary Performance, edited by Reason, Matthew and Anja, M. Lindelof, 271-277. London and New York: Routledge.

Blain, Martin. 2013. "Issues in instrumental design: The ontological problem (opportunity?) of 'liveness' for a laptop ensemble." Journal of Music, Technology and Education 6 (2): 191-206.

Bolt, Barbara. 2002. "The Techno-Sublime." Refractory: a Journal of Entertainment Media 1.

Brophy, Philip. 2010. "Vocalising the Posthuman." In Voice: Vocal Aesthetics in Digital Arts and Media, edited by Gibson, Ross, Norie Neumark and Theo van Leeuwen, 361-382. Cambridge, MA: MIT Press.

Camus, Albert. 1942, reprinted in 1946. The Stranger. New York: Vintage Books.

Chapple, Freda and Kattenbelt, Chiel, eds. 2006. Intermediality in Theatre and Performance. Amsterdam: Rodopi.

Crowther, Paul. 1993. Critical Aesthetics and Postmodernism. Oxford: Clarendon Press.

Emmerson, Simon. 2007. Living Electronic Music. Padstow: Ashgate.

Emmerson, Simon. 2011. "Music Imagination Technology." Proceedings of the International Computer Music Conference, Huddersfield, UK. 365-372.

Gough, Kathleen, M. 2016. "The Art of the Loop: Analogy, Aurality, History, Performance." The Drama Review 60 (1): 93-115.

Gilbert-Rolfe, Jeremy. 1999. Beauty and the Contemporary Sublime. New York: Allworth Press.

Home-Cook, George. 2015. Theatre and Aural Attention: Stretching Ourselves. Basingstoke: Palgrave Macmillan.

Kant, Immanuel. 1987. Critique of Judgment. Translated by Werner S. Pluhar. Indiana: Hackett.

Kattenbelt, Chiel. 2008. "Intermediality in Theatre and Performance: Definitions, Perceptions and Medial Relationships." Cultural, Language and Representation VI: 19-29.

Kramer, Jonathan, D. 1995. "Beyond unity: Towards an understanding of musical postmodernism." In, Concert music, rock, and jazz since 1945: essays and analytical studies, edited by Marvin, Elizabeth West, and Richard Hermann, 11-33. Rochester: University of Rochester Press. 
Lehmann, Hans-Thies. 2006. Postdramatic Theatre. Translated by Karen JürsMunby. Abingdon: Routledge.

Lepage, Robert and Charest, Rémy. 1997. Robert Lepage: Connecting flights. London: Methuen.

Risset, Jean-Claude. 1978. Paradoxes de hauteur. IRCAM

Roesner, David. 2014. Musicality in Theatre: Music as Model, Method and Metaphor in Theatre-Making. Farnham: Ashgate.

Schafer, Raymond Murray. 2005. "Foreword." In Sonic Experience: A Guide to Everyday Sounds, by Augoyard, Jean-François, and Henri Torgue, xi-xvi. London: McGill-Queen's University Press.

Shaw, Philip. 2006. The Sublime: The New Critical Idiom. London: Routledge.

Till, Nicholas. 2012. "Hearing Voices - Transcriptions of the Phonogram of a Schizophrenic: Music-theatre for Performer and Audio-visual Media." In Composed Theatre. Aesthetics, Practices, Processes, edited by Roesner, David, and Matthias Rebstock, 183-200. Bristol: Intellect.

Turner, Jane. 2016. "Sound and Subjectivity in the "Technosublime": Autobiographer and Ring." Journal of Dramatic Theory and Criticism 31 (2): 21-37.

The Good, the God and the Guillotine. By Proto-type Theater/MMUle. Directed by Andrew Westerside/Music composed by MMUle (Martin Blain, Nicholas Donovan, Paul J. Rogers). Nottingham Playhouse, Nottingham, May 29, 2014.

Westerside, Andrew. 2010. "Taste, Beauty, Sublime: Kantian Aesthetics and the Experience of Performance," PhD diss., University of Lancaster.

Wurth, Kiene. 2009. Musically Sublime: Indeterminacy, Infinity, Irresolvability. Oxford: Clarendon Press.

\section{Notes}

\footnotetext{
${ }^{1}$ Nottingham European Arts and Theatre Festival.

2 Pronounced, 'mule'.

${ }^{3}$ References to the spectator-listener throughout the article pertain to an outsider's perceptive/sensorial experience and follows Kiene Wurth's use of the term in Musically Sublime: Indeterminacy, Infinity, Irresolvability. 2009. OUP.

${ }^{4}$ Ostinato is a repeating musical pattern.

${ }^{5}$ To access a recording of 'Prologue' in relation to all references in this article see: https://vimeo.com/175210000.

${ }^{6} \mathrm{~J}-\mathrm{C}$. Risset (1978), in Paradoxes de hauteur, noted that the computer's ability to disassociate frequencies can create 'paradoxes' in chromatic scales whereby sound appears to rise or fall indefinitely (often referred to as the Shepard tone, after its creator). Thus, the degree of control over pitch, timbre and tone afforded by the MaxMSP patches allows a 'complexity and acoustic richness' that is commensurate with the 'incredible beauty' of sharawadji.

${ }^{7}$ See Blain $(2013,2016)$.

${ }^{8}$ To access a recording of 'Chapter 7: Monsieur Antichrist' in relation to all references in this article see: https://vimeo.com/175213154.

${ }^{9}$ To access a recording of 'Chapter 9: A Small Room that Smells of Darkness' in relation to all references in this article see: https://vimeo.com/175211672.

${ }^{10}$ Hocket is a compositional technique with its origins in the medieval period.
} 